\title{
Social Marketing Applications and Transportation Demand Management: An Information Instrument for the 21st Century
}

\author{
Enda McGovern, Institute of Transportation Studies, \\ University of California, Berkeley
}

\begin{abstract}
Concern has been expressed by planners and policy-makers that the "add capacity" strategy used in building more roads to resolve traffic-induced problems is no longer a feasible option. This article explores private transport behavior in understanding how users can be persuaded to adopt a more blended approach (i.e., integrating car, public transportation, and alternative modes on a daily basis). The research methodology adopted focus groups and travel diaries in presenting a number of social marketing message appeals aimed at inducing a change in participants' travel behaviors. While weaknesses are identified in the social marketing materials, this research concludes that social marketing as a stand-alone intervention program is not capable of persuading people to alter their overdependency on car use. Nonetheless, participants did acknowledge that the messages were informative and helpful in educating them on transportation issues. The research suggests that social marketing programs could be of value as information instruments in support of transportation demand management (TDM) policies. Such programs can function as an effective channel of communication in building dialog and garnering wider public support of
\end{abstract}


demand management policy and in delivering important transportation messages directly to commuters.

\section{Introduction}

Understanding a role for TDM is part of the problem facing policy-makers in truly determining the right course of action on transportation policy in the coming decades. How can TDM fit into the new horizon in dealing with transportation problems, given the perceived success to date of the "add-capacity" strategy? While there is an abundance of quantitative data available on this topic, in-depth qualitative data looking at the broader issues associated with transport behavior are somewhat scarce. This article attempts to contribute to the qualitative data construct by adopting focus group discussions and travel diary analysis as the methods of data collection.

An overview of the car industry in reference to its continued growth in numbers and applications worldwide is discussed. Social marketing theory is briefly reviewed in considering why the marketing principles adopted in everyday commercial applications cannot be used to better effect in situations where it may be particularly beneficial to society at large. In looking at the continued escalation of car use and associated travel behavior, this article presents a number of topics developed by the research participants as inhibiting their ability to more readily adopt other modes of sustainable transportation, such as public transportation, cycling, or walking.

\section{Transport Behavior}

In looking at concerns in the area of transportation, whether they are attributed to congestion, pollution, human health, or issues of safety, there are two general ways to reduce the economic, social, and environmental costs of transportation activities (Litman 2003). The first is to reduce impacts per unit of vehicle travel, generally in the form of developing engineering solutions by building more efficient road capacity or by other means, such as new innovative vehicle designs. The second approach is directed at the travel behavior element by either observing a reduction in total vehicle travel or by encouraging a reconfiguration of existing travel behavior in better utilizing the available transportation resources at hand. The general term for this is transportation demand management (TDM). This article focuses on the second approach in understanding how social marketing 
can make a positive contribution in determining more sustainable travel behavior decisions.

\section{The Car Industry}

At the end of 2000, there were more than 24 million cars registered in the UK, double the number registered in 1975. Over 70 percent of British households had regular use of a car in 1998-2000, and ownership was well spread among different sectors of the population (Social Trends 2002). In North America, some 16.6 million new cars and light trucks were delivered in 2003 alone as the auto industry overcame major obstacles, such as the war in Iraq, global economic uncertainty, oil production shortfalls and price spikes, and overcapacity, to record its fourth best year ever in total sales (Brandweek 2004). From 1950 to 1990, the number of vehicles in use worldwide grew from approximately 75 million to around 675 million (OECD 1997). While this period coincides with an improvement in economic conditions enjoyed by industrialized countries, it could therefore be speculated that the growth in car ownership was primarily linked to advances in prosperity, independence, and security. However, this shift in modal choice has created numerous problems for the environment.

Motor vehicle use is now generally recognized as the source of more air pollution than any other single human activity (Wiederkehr 1995:4).

Between 1990 and 2002, the levels of greenhouse gas emissions decreased in most sectors across the 15 countries of the European Union (EU-15), namely energy supply, industry, agriculture, and waste management. However, greenhouse emissions from transport-induced behavior actually increased by 22 percent in this same period (European Environment Agency 2004).

In the first few years of the 21st century, aside from the yet-to-be measured impact on travel behavior from the recent increases in the price of oil resulting in higher gas prices at the pumps, there seems to be little evidence to suggest that this phenomenon is about to decline. On the contrary, all indicators point to a protracted upswing in the utilization of private transport over the coming decades with few ideas forthcoming on how this may be contained. To cater to this ongoing demand across Europe, the length of the motorway network in the EU-15 grew by more than 25 percent between 1990 and 1999 to total nearly 50,000 km in 1999. As for the length of the rail network, identified as an alternative sustainable mode of public transportation, it contracted by 4 percent in the 1990s and by 1999 was 
just less than 154,000 km (Eurostat 2002). European statistics for 2000 record the UK as having 419 passenger cars per thousand citizens while the EU-15 average for the same year is recorded at 469 cars per thousand citizens (Energy \& Transportation DG 2002).

Another consequence of the continued growth in the use of private transportation is that individual access to motorized forms of transport has emerged as an important icon of progress in modern democratic societies. Consequently, the freedom of movement associated with access to this personal form of mobility is hard to suppress without fear of a hostile response from users.

Individual mobility is a cherished feature of the lifestyle in the economically affluent societies, satisfied by the ownership of one or more automobiles (Bauer 1996:686).

As a result national governments have been somewhat slow to challenge this behavior and have sought to stay clear of any obvious assault (e.g., punitive restrictions) on those people who adopt private transportation. The introduction of congestion charging, launched in central London in February 2003, was viewed as an exceptional public policy decision in dealing with London transportation problems by the designated public authority (Transportation for London 2003).

Instead, many governments offer their continuous support of the add-capacity strategy, namely the belief that transportation problems can be solved by simply building greater capacity into the infrastructure. However, recent evidence compiled by the Texas Transportation Institute (2004) would contradict this. The institute examined data collected from 1982 to 2002 in its analysis of 85 urban areas situated across the United States. The institute concluded that there are only a small number of areas, five in total, where travel demand was closely matched by the ability to supply adequate road capacity to meet this demand (see Figure 1). In the remainder of the areas, the Institute concludes that the level of demand has far outstripped the ability to construct an adequate capacity of supply to sufficiently meet this demand, allowing a 10-year timeframe from conception to completion for the majority of major road construction projects. The research suggests that there needs to be a corresponding growth in supply capacity at a rate slightly greater than travel growth to maintain constant travel times. However, this is not a workable solution, as it would require such road capacity to be constructed prior to the demand forming. This also makes the assumption that the add-capacity strategy is the only solution applied in attempting to address mobility concerns. 
Figure 1. Road Growth and Mobility Level (TTI 2004)

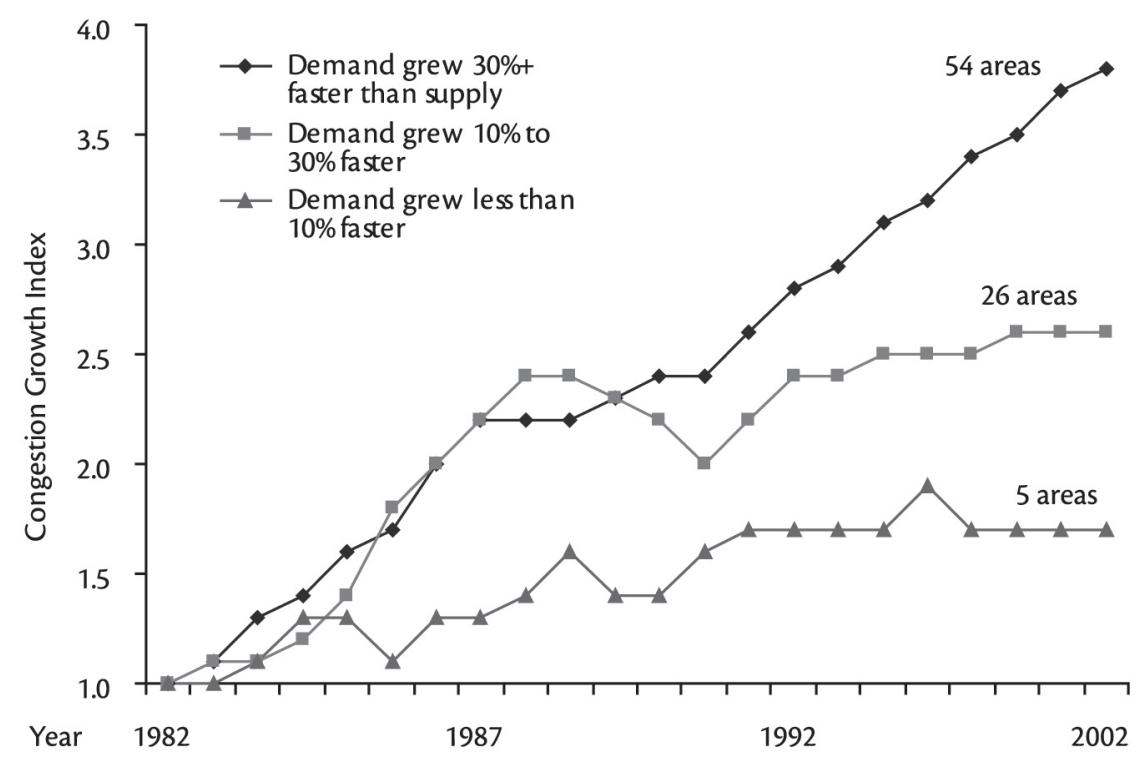

Source: Texas Transportation Institute 2004.

\section{Social Marketing}

Many marketing academics believe that the adoption of marketing theory in programs of social change can enhance the potential for success and, in many cases, is actually an integral part of their success. How can marketing theory therefore help foster a modified change in travel behavior, particularly in regard to encouraging the adoption of sustainable modes of transportation? Before one can consider the answer to this question, an understanding of where this area of research lies within the general field of academic marketing needs to be considered.

Presently there is a plethora of marketing terms that could be used in reference to this article. Among the terms commonly used are ecological marketing, social marketing, sustainable marketing, environmental marketing, and green marketing. Definitions of each are listed in the Table 1. 
Table 1. Definition of Terms

\begin{tabular}{|ll|}
\hline Term & Definition \\
\hline Marketing & $\begin{array}{l}\text { Human activity directed at satisfying needs and wants through exchange } \\
\text { processes (Kotler 1980:10). }\end{array}$ \\
Social Marketing & $\begin{array}{l}\text { The application of commercial marketing technologies to the analysis, } \\
\text { planning, execution, and evaluation of programs designed to influence the } \\
\text { voluntary behavior of target audiences in order to improve their personal } \\
\text { welfare and that of their society (Andreasen 1995:7). }\end{array}$ \\
Green Marketing & $\begin{array}{l}\text { The management process responsible for identifying, anticipating and } \\
\text { satisfying the requirements of consumers and society in a profitable and } \\
\text { sustainable way (Peattie 1992:11). }\end{array}$ \\
Sustainable & $\begin{array}{l}\text { Marketing efforts that are not only competitively sustainable but are also } \\
\text { ecologically sustainable (Sneth and Parvatiyar 1995:6). }\end{array}$ \\
Environmental & $\begin{array}{l}\text { Marketing activities that recognize environmental stewardship as a } \\
\text { business development responsibility and business growth opportunity } \\
\text { Marketing }\end{array}$
\end{tabular}

Any of the terms in Table 1 could be applied to the main theme of this research. Kotler (1979) argues that the objective of social marketing "is not to maximize consumption, consumer satisfaction, or consumer choice: The objective is to maximize the quality of life" (p. 85). Social marketing in its own right has become recognized only in the past two decades and is identified as the sector of marketing most applicable to this topic of interest.

Attempting to modify or alter people's behavior lies at the core of social marketing theory. In its formative years, social marketing was associated primarily with problems directly related to health. While much of the social marketing focus on health matters continues today, there have been continuing attempts to broaden its applications into other areas such as the planting of more trees, issues of child safety, and encouraging households to recycle (Andreasen 1995).

Implementing social marketing programs can be viewed as a policy option in fostering a sustainable transportation strategy. Such programs would be best 
described as information instruments in comparison to alternative instruments such as economic, regulatory, or cooperation (United Nations 2002).

The choice of transport modes, the acceptance of policy measures and the use of vehicles can be improved through moral suasion and transport-related education (United Nations 2002).

Providing relevant information that is targeted at individual travel behavior decisions can serve as a basis for more rational transportation decisions, and this is a prime focus of such approaches as 511.org, a free phone and web service that is being rolled out across the United States. The program consolidates transportation information into a one-stop resource, providing up-to-the-minute local information on traffic conditions, incidents and driving times, schedules, route and fare information for public transportation services, instant carpool and vanpool referrals, and bicycling information. The service is available 24 hours a day, 7 days a week. By the end of 2005, it is estimated that 511 will be operating in 25 states and that 50 percent of the U.S. population will have access to it ( 511 Deployment Coalition 2004). Communication efforts are making the public more aware of the benefits offered by the 511 service. Information instruments embrace many elements of social marketing, including public awareness campaigns, information distribution, and monitoring public attitudes on the use of such instruments in support of TDM policy.

\section{Research Methodology}

The research described in this article specifically set out to examine the framework of decision making among transportation users when selecting a mode of travel. Could private transportation users be persuaded to consider alternative modes of travel in removing themselves from an existing habitual decision-making process (i.e., choosing to perform a behavior without deliberation)? Or could social marketing programs support demand management policies to become more effective in reducing total vehicle travel or in other ways encouraging alternative modes to be considered?

The empirical research and analysis was undertaken in the UK between 1997 and 2000, and the research methodology was divided into two phases over a period of 10 months. Phase 1 of the research program adopted focus groups as the research instrument. Phase 2 of the research entailed an in-depth examination of the participants' travel behaviors in light of reviewing social marketing messages and was 
undertaken by recording their travel experiences as written text in the form of a diary. It is acknowledged, for purposes of this research, that commuters did identify the car as their primary mode of transport in use.

\section{Site Selection}

South Buckinghamshire District, located in the south of England, was identified as a suitable location for a number of reasons.

- The District was located on the outskirts of Greater London and close to many other forms of transportation, including mainline rail, underground, bus, and airline.

- A number of significant motorways passed through or alongside the boundary of the District. There are approximately $487 \mathrm{~km}$ of roads within the District and the M40, M25, and M4 motorways all pass through the District.

- It was determined that there would be a large commuting population living within and passing through the area.

Two parishes, Hedgerley and Gerrards Cross, were identified as research sites. See Figure 2 for a map of South Bucks District showing the parish boundaries.

\section{Phase 1}

Two focus group discussions were undertaken in each parish (four in total). The procedure for selecting participants was imparted to nominated parish coordinators, as they possessed knowledge of the local community and were familiar with the people who might participate in a research program. This kind of sampling is often referred to as judgmental or purposive sampling; that is, the sample elements are handpicked because it is expected that they can serve the research purpose (Churchill 1995). It was emphasized, through written guidelines passed to both co-coordinators, how essential it was for the selection procedure to be undertaken on an impartial basis as it was important to recruit a cross section of the population of interest. A broad cross section in age span was achieved, with ages ranging from 14 years to 76 years of age. Of the 34 people who participated in the research, 17 were female and 17 male-an equal split between genders. Overall, the sample set was deemed to be a fair representation of the demographic profile of each parish. 
Figure 2. Map of South Bucks District

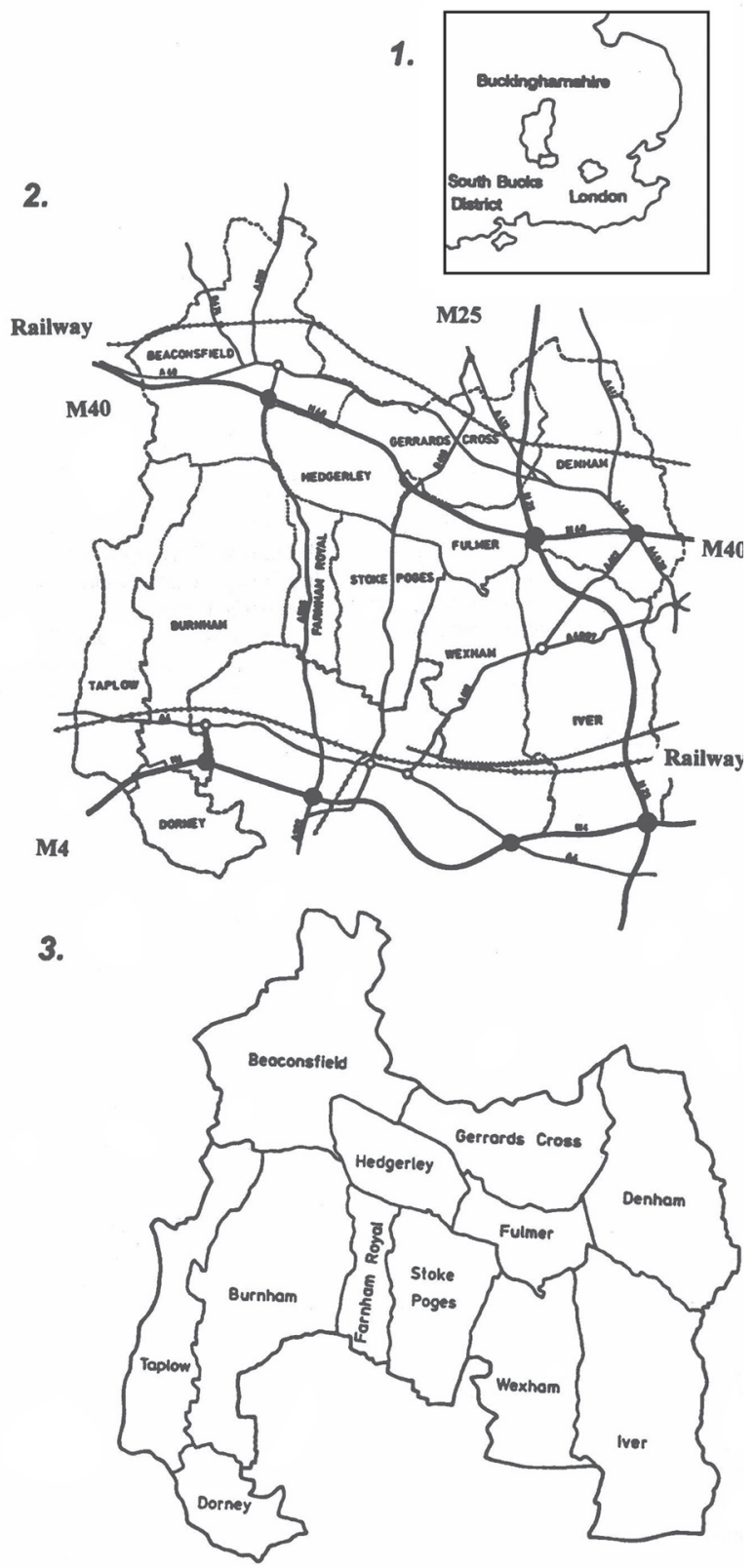

Source: South Bucks District Council 


\section{Phase 2}

The primary objective of Phase 2 was to further advance the quality and depth of the data acquired in Phase 1. A total of 24 households agreed to participate in Phase 2. The households were drawn from the original sample of 34 respondents. The research instrument adopted for Phase 2 was a travel diary in which respondents recorded travel history and, where possible, provided a narrative of why certain travel choices were made. A 10-week research timeframe was adopted and each household was required to record approximately 4 weeks of travel behavior during the 10-week period.

Initially, participants were asked to fill out a one-week diary cataloging the household's typical travel journeys. This task was intended to help participants focus on scrutinizing their existing patterns of travel behavior. The main part of the diary was concerned with determining cause-and-effect relationships between a mode of transportation and the rationale for that specific modal choice. This section was divided into three separate weeks and, at the beginning of each of these periods, household members were required to open a sealed envelope that contained social marketing material in the form of message appeals. Participants were asked to view the message appeals and to record to what extent the message appeal persuaded them to amend their travel behavior at that given moment in time. Even if the comments were negative (the message appeal had little or no effect), the household was still required to undertake three journeys within that week by adopting alternatives forms of transport to the car. The diary recorded the change of mode, purpose of journey, number of people traveling, and time of travel. There also were sections for the respondent to record positive and negative outcomes, along with the opportunity to explain whether the trip change would become permanent or remain temporary. It was critical for the success of the research that the households experienced other modes of transport not normally viewed as everyday choices. Based on these direct experiences, the respondents were encouraged to develop their thoughts and insights as written text in their diaries. Brief descriptions of the message appeals are presented below.

Message Appeal No. 1. Two versions of this appeal were distributed to the households, one aimed at promoting the annual Don't Choke Britain (DCB) campaign and the second published by Friends of the Earth (FoE).

Don't Choke Britain is a branded public awareness campaign that runs through the month of June each year. More than 300 local authorities take part in this 
"month of action." The Don't Choke Britain marketing material adopted the following wording:

Don't Choke Britain has simple aims: less traffic congestion and less pollution, particularly in our cities. Anyone can take part, very simply, by giving your car a holiday. Don't Choke Britain invites you to find another way of getting around on at least one day a week during June. Take a bus or train, walk or cycle, or share a car-everyone can do it!

The campaign's main message is to encourage participation in any one of the programmed events and thereafter to consider maintaining the resultant change in travel behavior. Examples of programmed events included:

- National Bike Week

- Green Transport Week (including Car Free Day)

- Walk to School Week

The second message appeal was in the form of a leaflet entitled "Cars Cost the Earth," published by the FoE. The leaflet (see Figure 3), produced as part of the

\section{Figure 3. "Cars Cost the Earth" Front Cover}

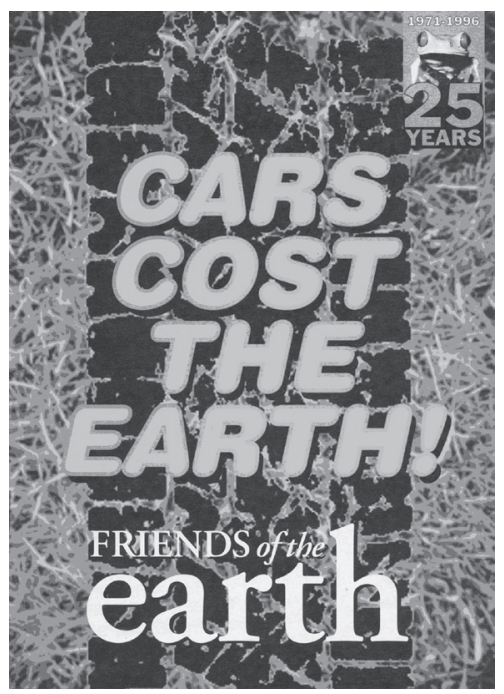

Source: Friends of the Earth (England, Wales, and Northern Ireland) 1996. 
FoE's 25 -year celebration, was 20 pages in length and more detailed than the DCB material. The principal message it conveys is: "It is time to rethink the way we travel, to reduce the number of cars on the road and to improve facilities for alternative ways of getting about such as walking, cycling and public transportation."

Message Appeal No. 2. This appeal consisted of a video entitled There is Another Way: TravelWise, which was produced by Buckinghamshire County Council and presented by the comedian Bill Oddie. The video is 10 minutes long and looks at traffic problems in the County of Buckinghamshire. Advice is provided on how to adopt a friendlier environmental mode of transport behavior. Most of the video was filmed in locations across Buckinghamshire, and this was considered beneficial if respondents, when viewing the video, identified locations with which they were familiar. A segment of the transcript is provided below.

Consider using the bicycle as an alternative form of travel. More bicycle lanes are being built and are becoming popular for both recreational and commuter use. They offer you the freedom to avoid congestion and enjoy the outdoors in a very relaxed manner.

Message Appeal No. 3. The final appeal took the form of a poster. A random selection of two posters from a total of four was chosen for each household. Each poster depicted a different theme and graphical imagery and in all cases photography was used to emphasize or support the message content. Wording used in each of the posters is provided in Table 2.

Table 2. Poster Wording

\begin{tabular}{|c|c|}
\hline Poster Number & Wording \\
\hline \multirow[t]{2}{*}{1} & Mummy, Why Do the School Run When We Can WALK? \\
\hline & $50 \%$ of all car journeys are less than 2 miles. \\
\hline \multirow[t]{2}{*}{2} & Daddy, What Did You Do In the War Against POLLUTION? \\
\hline & Cut car use, cut car pollution. \\
\hline \multirow[t]{2}{*}{3} & Get Home With Your Eyes Closed (Take the Train). \\
\hline & Cut car use, cut car pollution. \\
\hline 4 & When You Leave Your Car At Home, You Can Really Motor (by Bike). \\
\hline & Cut car use, cut car pollution. \\
\hline
\end{tabular}


These posters were designed by the Essex County Council as part of their TravelWise public information program and were widely displayed on buses throughout the County.

\section{Data Analysis}

This author adopted the framework concept (Ritchie and Spencer 1994) for this research program. This analytical process involves a number of distinct though highly interconnected stages. It was developed for use with applied qualitative research through its requirements to meet specific information needs and its potential for actionable outcomes. The five key stages to qualitative data analysis involved in the framework concept are:

1. Familiarization

2. Identifying a thematic framework

3. Indexing

4. Charting

5. Mapping and interpretation

These five stages can act as pathways for the analyst to refer to during the ongoing analysis of the data. Constantly working and reworking the data by sorting, sifting, and charting will enable the analyst to be creative and imaginative yet still maintain control of the material. These stages can be presented in a number of different ways and include familiarization, cataloging, conceptualization, and linkages among others.

Ritchie and Spencer (1994) remark:

....although systematic and disciplined, it (the "framework") relies on the creative and conceptual ability of the analyst to determine meaning, salience and connections. Real leaps in analytical thinking often involve both jumping ahead and returning to rework earlier ideas ( $p$. 177).

When the focus groups were completed, the cassette tapes were given to a professional transcriber who converted the narrative to text. The author then started scrutinizing the text in detail to identify a thematic framework. This was undertaken using a color-coding system as a form of indexing. In each focus group, themes were identified and traced by marking the conversation with the same color throughout the body of the text. This was a very efficient way of pouring 
over the text, as it was easy to make connections and offer up specifics in support of common themes. The diaries were examined in detail in a similar way to try and ascertain the nuances between family members when making decisions regarding specific journeys. The diaries were also analyzed to uncover what the reaction was when a specific message appeal was opened in front of all the family members. In many cases, comments and subsequent points were recorded in the diaries, allowing a rich vein of data to be gathered at that specific point in time. This information was expanded upon with further entries made in the following week.

\section{Analysis of Feedback on Message Appeals}

Of the three formats adopted in the message appeals, both the video and the posters achieved a reasonable amount of support, while there was negative commentary expressed about the leaflets.

\section{Message Appeal No. 1}

Comments made about both leaflets were generally discouraging, and the respondents offered numerous reasons for such responses. The Don't Choke Britain leaflet received widespread criticism directed at what respondents referred to as the "flawed design" of the artwork. These comments implied that the visual component of the leaflet was not only poorly received but, to some extent, turned people off before they even began to interpret the message. Participants' comments included:

- "Don't Choke Britain suffers from a rather garish front cover that, at first sight, suggests that ferry boats, kites, and trains do something unpleasant to young children."

- "I particularly dislike the Don't Choke Britain Campaign leaflet. Bad colors, bad presentation on cover and totally alienating. I would not have bothered to read it if I had not been doing the research."

Judging from the comments below, the "Cars Cost the Earth" leaflet was perceived by the participants as confusing.

- "Too much varied information to take in. Could have been better if they concentrated on a few main points."

- "Interesting but too negative in just pushing pollution issue. If my car is wrong, then what about big business, worst pollutants." 


\section{Message Appeal No. 2}

The video format was strongly endorsed by households as a very effective means of transmitting the message. Comments included:

- "Video was good and put over with a sense of humor, which helped."

- "Certainly made me think about opportunities to change. Given my travel profile, however, the only opportunity I have to change are trips to Gerrards Cross or church. Both of these I change when time permits. The pace of life demands at least reasonably fast transport times. Public transportation isn't an option. Why isn't there a train service to go around the M25?"

\section{Message Appeal No. 3}

The posters received the broadest level of acceptance and elicited very warm responses even though this format adopted only a maximum of 20 words with a creative piece of artwork. Comments included:

- "Brilliant message appeal. Clear and straight to the point."

- "I like the school poster. That is a conscience pricker."

- "Made me feel quite uncomfortable, at least in regard to transporting our children to school and my commuting. But did it do anything now? Not much!"

- "Does make you feel guilty about very short car journeys!"

It is not clear why the posters were so well received by a large section of the households. It could be that the message was plain, clear, and to the point and that this encouraged an immediate level of agreement from the respondents.

\section{Research Findings}

A review of the major findings identified in the research as having a significant bearing on travel behavior decisions is presented below.

\section{The Responsibilities of Different Generations}

What did the research have to say about "age" in the context of people's transportation behavior? On the issue of risk, it was noticeable how the older participants viewed this theme as compared to that of the younger participants. On a number of occasions, the older participants asked the younger ones when they would begin to change their travel behavior! In one example, a 75-year-old participant verbalized this thought directly when he pointed to two of the younger partici- 
pants across the table and said, "The ones that are going to make the decision for us are the two youngsters there because in my time it is just going to make no difference".

There was agreement by many of the older participants on this point. They considered that the time left in their lives was too short to be of any benefit in solving the long-term problems ahead. Nonetheless, the younger participants quickly voiced their disagreement on this point. Use of a car was an expression of freedom for them, and it was their intention to get the opportunity to enjoy driving without any further restrictions being placed on them. During the discussions, many of the younger participants claimed they needed access to a car in order to lead a normal social life.

Judging from the dialog among the participants, one could surmise that the older participants are waiting for the younger ones to undertake the desired behavior changes, while the younger participants are waiting for the scientific community to come up with solutions to these problems. This is a further example of the disconnect between individual responsibility and a lack of understanding of the problems associated with this responsibility.

\section{A Sense of Powerlessness}

Participants expressed the belief that they are not consulted and therefore have no influence or power in addressing the transportation issues raised, specifically in regard to their own locality. They reflect on the fact that there are no provisions for them to either express their concerns or to put forward possible solutions. Acknowledgment of this during the discussions seemed to generate a degree of skepticism among the participants in their dealings with the authorities, particularly the local authorities. The participants believe that these authorities do not always take the correct action or, more importantly, take any action at all.

Examples of this sense of powerlessness abound in the discussions, especially regarding the performance of the bus companies. Many of participants are of the view that, as the bus companies are now privatized, the public has no voice or controlling power in setting the criteria for an acceptable level of service. Problems with the scheduling and canceling of services at short notice are one example, and it is continuously referred to as an issue of concern.

However, the local authorities may be doing their best to seek the opinions of the residents already. Publication of "The Draft State of the Environment Report" by the Bucks District Council seemed to be a genuine attempt at this endeavor. In 
releasing the report, the Council held a public meeting and invited representatives from all the parishes within the District. The Council clearly requested people to respond to issues raised in the report, but it was obvious that the majority of the participants were unaware that this report had been published. The research concludes that the local authorities need to constantly review their efforts at communicating with the public on local transportation-related issues and to understand that there needs to be "buy-in" from the local community in decisions related to transportation policy. Ignoring the buy-in factor only leads to local people feeling frustrated and unwilling to support transportation policy at large.

\section{Poor Image of Public Transportation}

A key influence for the participants when considering alternative modes of travel was the poor image they held of public transportation. Many examples were recounted of buses not running, train timetables not being followed, and difficulties in finding fares for specific journeys. Such experiences caused much frustration and resulted in people not considering public transportation as an alternative modal choice.

This point is extended further by the continuous reference throughout the discussions on the issue of poor timetabling. The timetable was of importance because the participants interpreted it as a form of contract or as a declaration of commitment by the transportation company to provide them as passengers with certain travel services. However, the respondents quickly determined that the timetable was of little value as they confirmed that the bus companies rarely adhered to it with any sense of urgency.

This poor image of public transportation also seems to have generated a lack of trust among participants in the information being provided by the public transportation providers. Participants claimed they were initially prepared to work through difficult situations when adopting public transportation but that this had now become unworkable as they were being continuously "let down." These problems had been ongoing for a number of years, and the participants expressed a degree of anger that they still had to hear the same excuses. The participants expressed reservations if public transportation could ever be adequately improved for them to adopt it with a degree of confidence.

\section{A Sense of Security or Lack of It}

The issue of security was identified as playing a significant part in influencing the decision to select a specific mode of transportation. All the participants enjoyed 
the security and freedom associated with the adoption of private transportation. Through this mode, the participants had the freedom to decide when to travel and how long to take to get there (in normal circumstances), felt safer about undertaking the journey, listened to the radio, and yet could still make changes to their own itinerary if desired. The freedom associated with being able to choose the car lay at the core of the participants' lifestyles and they all wanted to maintain it without any disruption.

It could be argued from the research findings that the issue of personal safety is one of the main reasons people are adopting private transportation in greater numbers. This was inferred in the discussions when reference was made to the fact that households were becoming "insular" in the way they lead their lives, or how "artificial bubbles" were being created to allow households to feel more secure when undertaking day-to-day journeys. While the participants expressed how difficult it is to feel completely safe in any mode of transportation, there was general consensus that private transportation provided the greatest sense of safety for those who consider it a priority. However, the issue of personal safety carried with it a negative consequence for many of the participants contemplating public transportation.

\section{Site Selection}

The households selected in the two parishes are not representative of the average UK household. The sites could be classified as a middle- to upper-class locations. As a result, it is accepted that the findings of this research are relatively unique to this research area. Does that make the evidence gathered of less consequence? The author strongly argues that this is not the case for the following reasons.

The focus group discussions raised issues that are commonly discussed on a dayto-day basis when it comes to problems of transportation. "The buses are late," "the train is delayed," "the cars are speeding," or "the pollution is terrible" are comments that can be heard daily. Therefore, the opportunity to record such issues in depth in the Hedgerley and Gerrards Cross parishes was an invaluable source of data. And the availability of such data to the research community at large, while specific to this research site, would be of value in the search for long-term solutions.

The same can also be said of the diary panel data. The opportunity for people to self-report on their travel behavior over an extended period of time is an opportunity to collect valuable data. It would be reasonable to assume that there are 
no two households in the UK that have the exact same demands on their time and how they make their journeys to work or school. However, having access to data that are self-compiled from within the household and that offer insights on journeys made under different modes of transportation can be very productive in contributing to the wider issues of the research.

\section{Conclusions}

This article explores the use of social marketing applications as information instruments in the field of transportation studies. Although the social marketing programs reviewed provided no evidence of prolonged mode change among the people studied, the participants did acknowledge that they considered the messages informative and helpful in educating them on some of the sensitive issues regarding transportation choices and the decision-making process involved. While the research did not record specific behavior change, it could be argued that participants may have subconsciously altered their transport behavior based on their participation in this research. One could conclude that such information can influence a participant's psychological thinking in the form of previous held beliefs, attitudes, or habits.

It is too early to discount any future role that social marketing may play in the area of transport behavior. More primary data, accurately sourced and collected, are required from the appropriate audiences if successful campaigns are to be designed. These campaigns, in turn, require adequate funding to enable professionally-managed programs to be created. Only if these considerations are taken account can social marketing campaigns be truly tested in helping to change peoples' attitudes and behavior toward transport.

At the outset of the research, an emphasis was placed on persuading car users to be more flexible with their travel needs and expectations, with the intention of promoting alternative modes of travel in their choice set. To do this successfully, and to be able to produce the appropriate social marketing appeals, the research has provided evidence that the designated authority must first gain a deeper appreciation of the issues facing the everyday commuter. The needs of the commuter can only be accurately appraised if research is undertaken that facilitates an extended period of consultation. This article suggests such research needs to be based on transportation behavior undertaken within local districts to fully understand the specific commuter dynamics associated with each district. Undertaking 
research on a broader scale, either regionally or nationally, may be beneficial for statistical purposes. However, this wider approach can result in data becoming detached from the specific psychological issues at play that are closely connected to the physical environment of each district. Social marketers, primed with this indepth knowledge, can create more effective social marketing programs in support of TDM policy with a greater potential to achieve the desired behavioral changes.

The topics examined in this article are an essential part of the dialog that needs to be generated with the relevant constituencies in discussing transportation and quality-of-life issues. The major findings of the research project could therefore be summarized as follows:

- There are different opinions from across the spectrum of participants as to what actions should be taken and who should bear the responsibility for undertaking them.

- The participants have a feeling of powerlessness and believe that there is no effective forum for them to express their views.

- The poor image of public transportation conveyed in the public domain is seriously undermining its consideration as an alternative mode of travel.

- There is a strong sense that private transportation provides a much greater degree of security and comfort than that provided by other modes of transportation.

- The research has taken into account that the residents of Gerrards Cross and Hedgerley are not representative of the average UK household.

\section{Limitations and Future Research}

The research emphasis was to acquire an awareness of the motivation that lies behind a person's thinking when choosing a mode of transport. This required a methodology with no restrictions or boundaries on the data to be collected but rather the adoption of research instruments that would allow an open forum for participants to honestly discuss the topic. For the success of the study, it was essential that participants be allowed to elaborate on their own experiences within their own frame of reference. The combination of focus group and travel diary instruments was deemed suitable for this purpose. Nevertheless, there are obvious difficulties to be aware of when opting for qualitative research. The focus is on the use of language, and it is observed that there are no mechanical procedures available to interpret the findings. Consequently, labor intensity and the 
possibility of researcher bias are genuine concerns associated with this research methodology.

What are the opportunities for further research in support of social marketing programs as information instruments? As a sequel to this article, it is appropriate to offer some suggestions in the form of recommendations that could be of assistance to academics, practitioners, and public agencies in the search for workable solutions. It is recommended that campaigns consider stressing the direct benefits of all modes of transport as appropriate to particular journeys or situations. In effect, this embraces the concept of intermodality to better package the desired behavior. It is not enough to expect commuters to switch from private transport to public transport just by producing negative advertising campaigns about the environmental damage generated by private transport. This is clearly an ineffective approach as the research has shown.

How commuters respond to current campaigns should be evaluated and incorporated into future social marketing programs. This is important as social marketing programs need to become more accountable in defending how well they meet their overall objectives. This requires social marketers to be more aware, for example, of how many people may hold a particular belief before they commit resources designed to rectify any associated behavior. In other words, hard background data need to be compiled prior to the commencement of any campaign so that accurate measurements of outcomes can be reviewed during or after a program has run. During the course of this research, there was little indication of any formative evaluation processes being practiced by any of the authorities concerned.

The research also recommends that a dual approach be considered when communicating with the public on this subject. A parallel strategy of informing the public of the benefits to be gained from adopting alternatives modes could be undertaken, while at the same time executing a program of communication designed to enhance the profile of the alternative modes on offer. The marketing of alternative forms of transport, especially public transportation, needs to be proactively branded among the traveling population rather than presented, or perceived, as a poor substitution to the automobile.

Finally, further research should attempt to augment the standing of social marketing in the specific area of transport behavior. Research emphasis should be placed on social marketing applications within the transport domain that show the most promise in engaging behavior change (i.e., target the resources wisely). In particu- 
lar, this research could help to enlighten policy-makers who, while at the center of transport policy, could benefit greatly from understanding how social marketers can make a valuable contribution to this area of human behavior.

\section{Acknowledgments}

The author would like to thank Prof. Marty Wachs of the University of California, Berkeley for his invaluable input and the reviewers for their helpful comments as part of the blind review process in compiling this article.

\section{References}

Andreasen, A. 1995. Marketing Social Change: Changing Behavior to Promote Health, Social Development, and the Environment. San Francisco: Jossey-Bass Publishers.

Bauer, M. 1996. Transport and the environment: Can technology provide the answers? Energy Policy 24 (8): 685-687.

Brandweek. 2004. In tight market, car makers seek branding alternatives Brandweek 45 (25): S22.

Churchill, G. 1995. Marketing research: Methodological Foundations, 6th ed. Fort Worth: The Dryden Press.

Coddington, W. 1993. Environmental Marketing: Positive Strategies for Reaching the Green Consumer. New York: McGraw-Hill.

European Environment Agency. 2004. Greenhouse gas emissions trends and projections in Europe 2004. Luxembourg: EEA Report (5).

Eurostat. 2002.Transport infrastructure in Europe between 1990 and 1999. Brussels.

Energy \& Transportation DG. 2002. http://europa.eu.int/comm/energy_transport/ etif/transport_means_road/motorization.html.

Kotler, P. 1980. Marketing Management: Analysis, Planning and Control, 4th ed. Eaglewood NJ: Prentice Hall Inc. 
Kotler, P. 1979. Axioms for social marketing. In Fisk G., Arndt J., and Gronharg K., eds., Future Direction for Marketing. Boston: Marketing Science Institute, pp. 33-41.

Litman, T. 2003. Transportation demand management and "win-win" transportation solutions." In Hensher, D., and K. Button, eds., Handbook of Transport and the Environment. Amsterdam: Elsevier, 805-814.

OECD (Organization for Economic Co-Operation and Development). 1997. Sustainable consumption and individual travel behavior: Report of the OECD Policy Meeting. Paris: OCDE/GD(97)144.

Peattie, K. 1992. Green Marketing. The M\&E Handbook Series. London: Longman.

Ritchie, J., and L. Spencer. 1994. Qualitative data analysis for applied policy research. In Bryman A., and Burgess R., eds., Analyzing Qualitative Data. London: Routledge.

Sneth, J., and A. Parvatiyar. 1995. Ecological imperatives and the role of marketing. In Polonsky M. and Mintu-Wimsatt A., eds., Environmental Marketing: Strategies, Practice, Theories, and Research. New York: The Haworth Press, pp.3-20.

Social Trends. 2002. Households with regular use of a car: By age of head of household, 1998-2000. Office for National Statistics, London (32).

TfL. 2004. http://www.londontransport.co.uk/tfl/press-releases/2004/february/ press-932.shtml.

Texas Transportation Institute. 2004. The 2004 urban mobility report. http://tti. tamu.edu.

Transportation for London. 2003. Central London congestion charging scheme: Three months on. London: Congestion Charging Division.

United Nations. 2002. Policy guidelines for road transport pricing: A practical stepby-step approach. Economic and Social Commission for Asia and the Pacific and GTZ GmBH, New York.

Wiederkehr, P. 1995. Motor vehicle population: Reduction strategies beyond 2010. Paris: Organization for Economic Co-operation and Development.

511 Deployment Coalition. 2004. National Progress Report. ITS America, www. deploy511.org. 


\section{About the Author}

ENDA MCGoverN, (mcgoverne2@southernct.edu) is an Associate Professor of Marketing in the School of Business at Southern Connecticut State University. Until recently he held the position of Visiting Scholar at the Institute of Transportation Studies at UC Berkeley. His primary degree is in Civil Engineering, having then obtained an MBA in 1988 and his PhD in Social Marketing from Brunel University, London, in 2000. His research interests include social marketing, travel demand management, and public policy. Prior to joining the Faculty at Southern Connecticut State University, Dr. McGovern was on the faculty at Dominican University of California and was a tenured faculty member in the School of Management, Brunel University, London. 